\title{
Diet and faecal flora in the newborn: nucleotides
}

\author{
S E Balmer, L S Hanvey, B A Wharton
}

\begin{abstract}
Breast milk contains nucleotide salts that are only present in minimal amounts in modern infant formulas prepared from cows' milk. Nucleotides have been suggested as cofactors for the growth of bifidobacteria in vitro. Bifidobacteria are found to be more numerous in the faeces of breast fed babies compared with those of formula fed babies.

Faecal flora were examined at 2 weeks of age in 32 babies who from birth had been fed a whey based formula supplemented with nucleotide monophosphate salts, 33 babies fed an unsupplemented formula, and 21 breast fed babies. Faecal flora were also examined at 4 weeks, and 7 weeks but with fewer babies in each group.

Most differences were found at 2 weeks of age when more babies fed the nucleotide supplemented formula were colonised with Escherichia coli and more had $E$ coli as the dominant organism in their faecal flora. Fewer of these babies were colonised with bifidobacteria. The counts of bifidobacteria and enterococci were reduced in the nucleotide supplemented group but bacteroides accounted for a higher percentage of the total flora in
\end{abstract}

this group of babies. Supplementation of a formula with nucleotide salts did not make the faecal flora closer to that of breast fed infants as the growth of bifidobacteria was discouraged.

While there may be arguments to support the addition of nucleotides to infant formula the results of this study do not support their addition for the enhancement of bifidobacteria in the faecal flora. (Arch Dis Child 1994; 70: F137-F140)

In previous studies we have shown that the faecal flora of a breast fed baby is quite different from that of a normal formula fed baby. ${ }^{1-4}$ Breast fed babies were always found to have a predominance of commensal organisms such as bifidobacteria in their faeces, whereas in bottle fed babies there were large numbers of potential pathogens such as Escherichia coli. Dietary factors such as bovine lactoferrin, iron, and the casein/whey ratio were studied to establish their effects on the flora, both singly and in combination. Of the dietary factors examined a whey based formula without added iron or bovine lactoferrin produced a faecal flora closest to that of a breast fed baby but it was still very different.

Other factors in breast milk that could be responsible for this difference in faecal flora are numerous but one possibility is the nucleotides present in breast milk but present in trace amounts in formulas prepared from cows' milk. There has been recent interest in dietary nucleotides as 'conditionally essential nutrients' and some evidence that they enhance certain functions such as cellular immunity, lipid metabolism, and the intestinal response to injury in the newborn. ${ }^{5-8}$ Furthermore, in vitro studies have shown that nucleotides can act as growth factors for some strains of bifidobacteria. ${ }^{9}{ }^{10}$ One in vivo study has suggested that the addition of nucleotides to an infant formula enhances the growth of bifidobacteria in the gut of newborn babies. ${ }^{11}$

This study examines further the effect of dietary nucleotides in vivo on the faecal flora of newborn babies.

\section{Subjects and methods}

DIET AND BABIES

Mothers from one postnatal ward at Sorrento Maternity Hospital in Birmingham, who had delivered vaginally a normal baby at term, weighing more than $2500 \mathrm{~g}$, and who had definitely decided not to breast feed, were invited to take part in the study. If they agreed and gave written consent their baby was assigned to the formula that was on offer during that week. Two formulas were available and the one
No of babies

Week 7

No of babies

22

23 

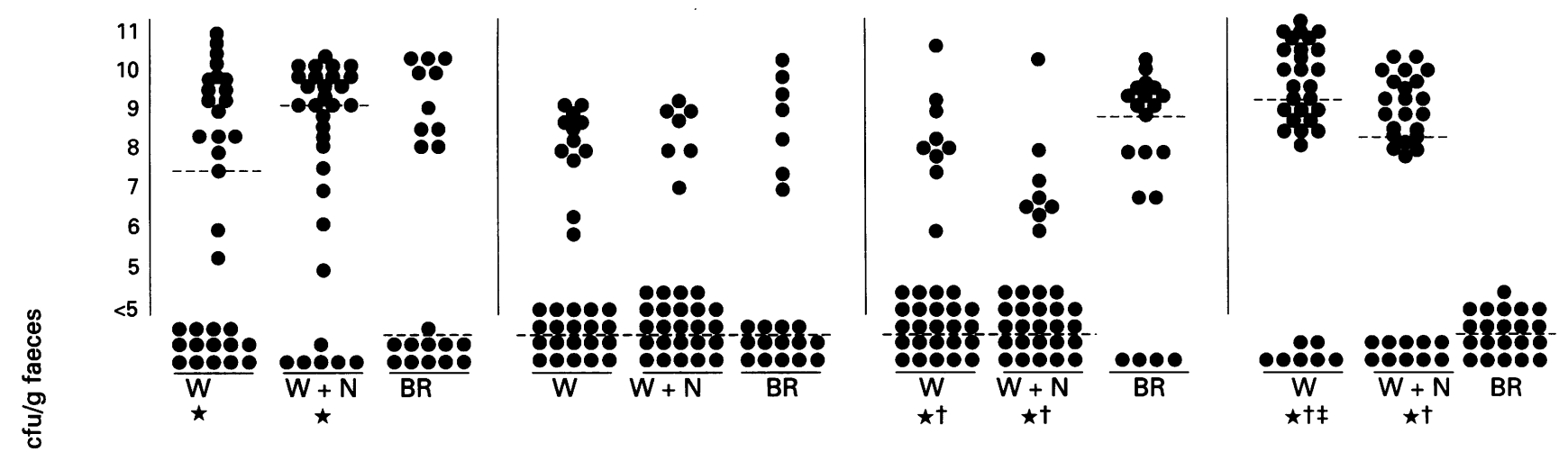

웅
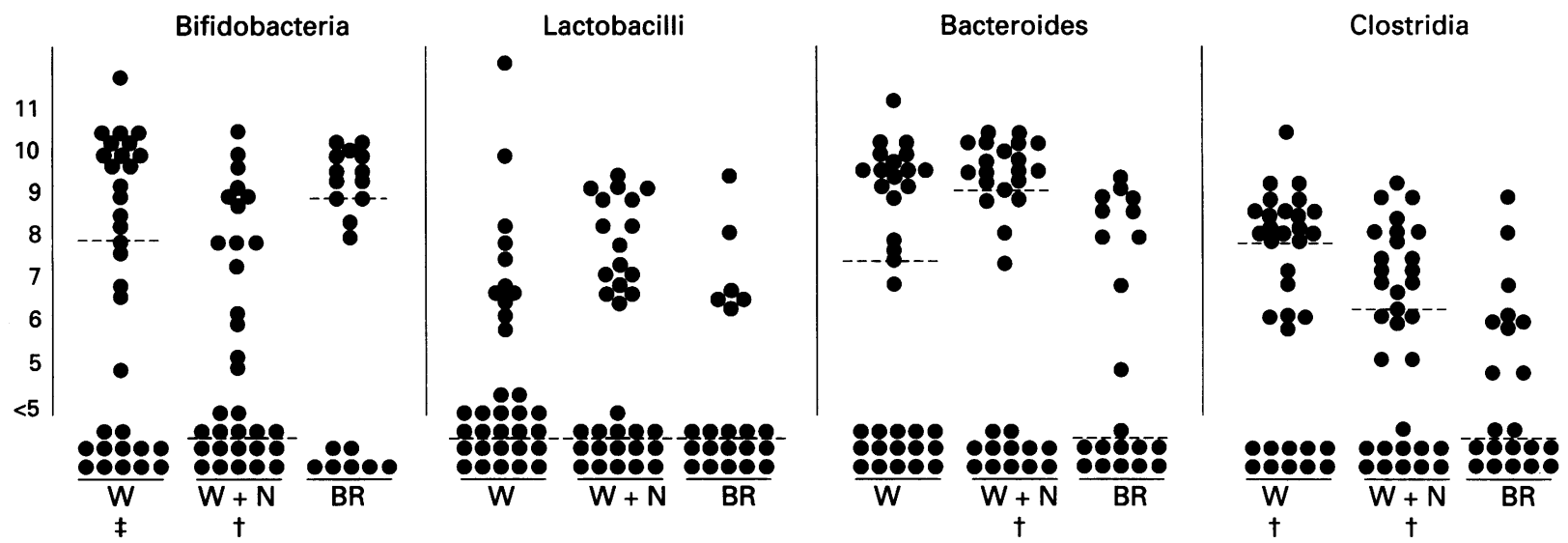

Figure 1 Counts of individual organisms ( $\log _{10}$ colony forming units (cfu)/g wet faeces) at 2 weeks. Median count shown by a horizontal broken line. $W$, whey unsupplemented formula; $W+N$, whey formula supplemented with nucleotides; $B R$, breast fed. *Number of babies colonised significantly different from breast fed babies $(p<0.05$ ). †Counts in faeces of formula fed babies significantly different from those found in breast fed babies ( $p<0.05)$. $\ddagger$ Counts in faeces of unsupplemented whey fed babies (W) significantly different to those from babies fed the nucleotide supplemented formula (W+N) $(p<0 \cdot 05)$.

Table 3 Composition of faecal flora at week 4 (counts expressed as $\times 10^{9}$ colony forming units/g wet weight)

\begin{tabular}{|c|c|c|c|}
\hline & \multicolumn{2}{|l|}{ Formula } & \multirow[b]{2}{*}{$\begin{array}{l}\text { Breast milk } \\
(n=12)\end{array}$} \\
\hline & $\begin{array}{l}\text { Whey with iron: } \\
\text { no added nucleotides (W) } \\
(n=26)\end{array}$ & $\begin{array}{l}\text { Whey with iron: } \\
\text { added nucleotides }(W+N) \\
(n=25)\end{array}$ & \\
\hline \multicolumn{4}{|l|}{ E coli } \\
\hline No $(\%)$ babies colonised & $22(85)$ & $18(72)$ & $9(75)$ \\
\hline Median count & 0.3 & 0.1 & 0.15 \\
\hline Range of counts & $0-30$ & $0-6 \cdot 0$ & $0-5 \cdot 0$ \\
\hline \multicolumn{4}{|l|}{ Other coliforms } \\
\hline No $(\%)$ babies colonised & $11(42)$ & $5(20)$ & $2(17)$ \\
\hline Median count & & & 0 \\
\hline \multirow{2}{*}{\multicolumn{4}{|c|}{ Staphylococci }} \\
\hline & & & \\
\hline $\begin{array}{l}\text { No }(\%) \text { babies colonised } \\
\text { Median count }\end{array}$ & $\begin{array}{l}4(15)^{\star} \\
0 \ddagger\end{array}$ & $\begin{array}{l}4(16)^{\star} \\
0 \ddagger\end{array}$ & $\begin{array}{l}9(75) \\
0.004\end{array}$ \\
\hline Range of counts & $0-0.005$ & $0-0.04$ & $0-2 \cdot 0$ \\
\hline \multicolumn{4}{|l|}{ Enterococci } \\
\hline No (\%) babies colonised & $20(77)^{\star} \dagger$ & $24(96)^{\star}$ & $5(42)$ \\
\hline Median count & $1.0 \ddagger$ & $1.0 \ddagger$ & \\
\hline Range of counts & $0-50$ & $0-8$ & $0-7 \cdot 0$ \\
\hline \multicolumn{4}{|l|}{ Bifidobacteria } \\
\hline No $(\%)$ babies colonised & $17(65)$ & $11(44)$ & $8(67)$ \\
\hline Median count & 0.01 & & $1 \cdot 0$ \\
\hline Range of counts & $0-200$ & $0-40$ & $0-30$ \\
\hline \multicolumn{4}{|l|}{ Lactobacilli } \\
\hline No $(\%)$ babies colonised & $11(42)$ & $11(44)$ & $6(50)$ \\
\hline Median count & & & \\
\hline Range of counts & $0-500$ & $0-0.5$ & $0-0.3$ \\
\hline \multicolumn{4}{|l|}{ Bacteroides } \\
\hline No $(\%)$ babies colonised & $17(65)$ & $15(60)$ & $4(33)$ \\
\hline Median count & $2 \cdot 0$ & $1 \cdot 0$ & \\
\hline Range of counts & $0-40$ & $0-70$ & $0-4 \cdot 0$ \\
\hline \multicolumn{4}{|l|}{ Clostridia } \\
\hline No $(\%)$ babies colonised & $12(46)$ & $13(52)$ & $8(67)$ \\
\hline Median count & 0 & 0.00001 & 0.001 \\
\hline Range of counts & $0-0.2$ & $0-08.03$ & $0-0 \cdot 7$ \\
\hline
\end{tabular}

Significant differences by $\chi^{2}$ test: *different from breast fed babies, + different from babies fed $\mathbb{W}+\mathbf{N}$; by Mann Whitney test: $\ddagger$ different from babies fed $W+N$. offered was changed weekly. Once assigned to a study formula the baby received the same formula for seven weeks. The formulas were specially prepared by Wyeth Ayerst and were based on SMA Gold, a whey dominant formula with added iron, with $(\mathrm{W}+\mathrm{N})$ and without (W) added nucleotides (table 1). They were supplied as liquid ready to feed formulas in glass bottles for the first 14 days of feeding and in combi blocks thereafter. Breast fed babies from the same ward were also recruited for the study. The details of all babies are shown in table 2. Anthropometric measurements were taken at 2,4 , and 7 weeks and there was no difference in growth and weight gain in the three dietary groups during the period of the study.

\section{PROCEDURES}

Faeces were collected at weeks 2, 4, and 7. The methods for collection, transport, storage, and for the microbiological examination of faeces were exactly as described in the previous studies in this series. ${ }^{1}$

STATISTICAL ANALYSIS

The results were analysed using the MannWhitney and Wilcoxon tests for the comparison of distributions (actual counts of bacteria) 


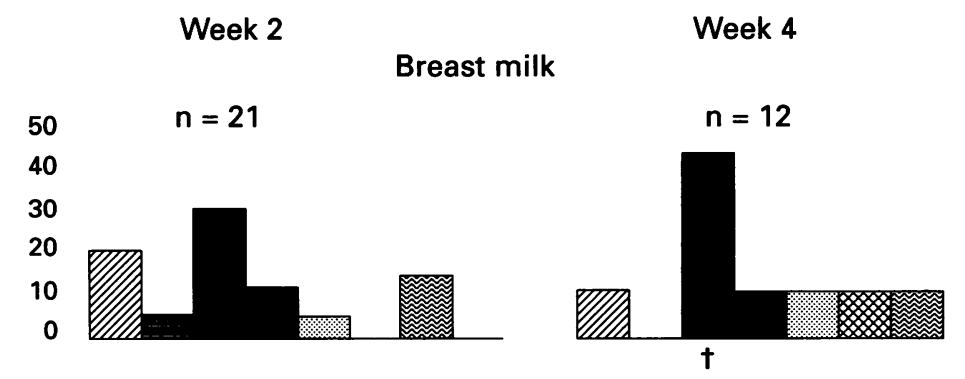

Formula - no added nucleotides (W)
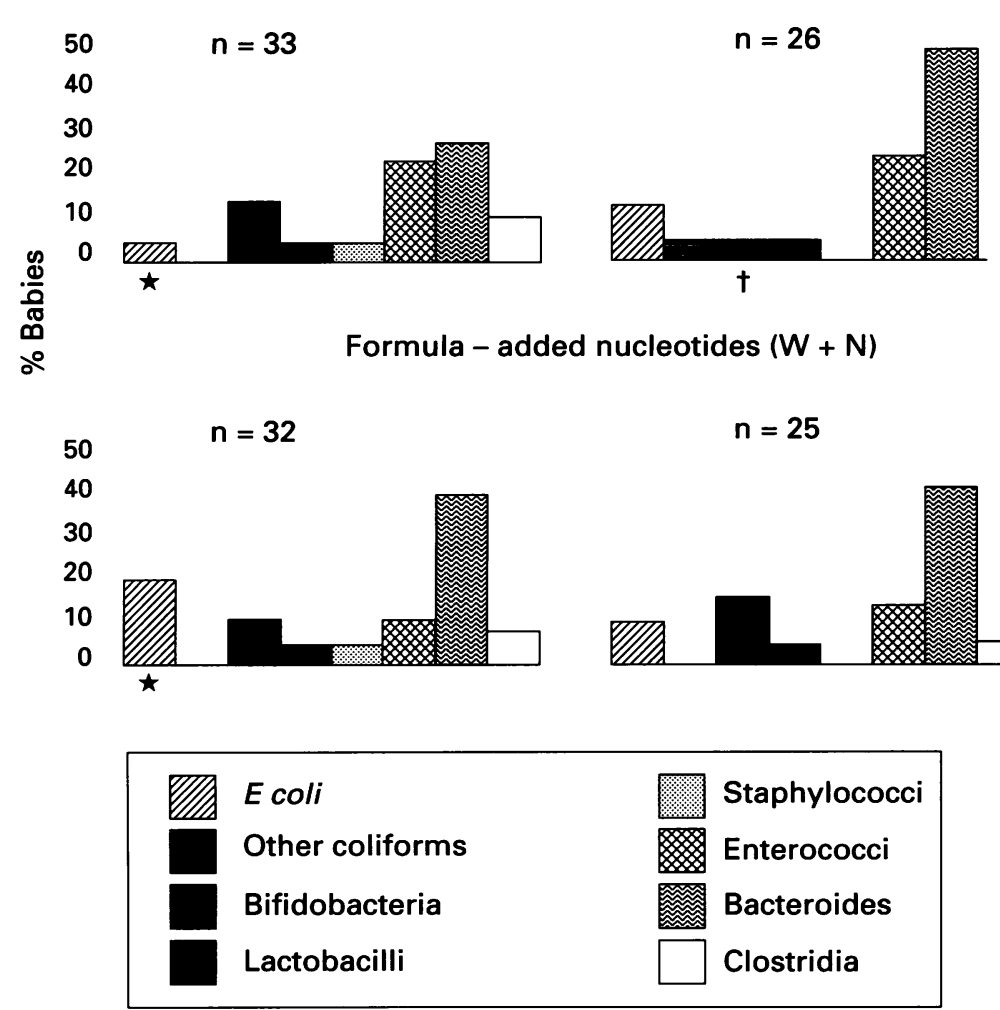

Figure 2 Percentage of babies in whose faeces an organism was dominant (that is the greatest count) at 2 and 4 weeks. ${ }^{\star}$ Unsupplemented formula fed babies (W) significantly different from nucleotide supplemented formula fed babies $(W+N)(p=0.043)$. †Unsupplemented formula fed babies (W) significantly different from breast fed babies $(p=0.0074)$.

\section{COUNTS OF INDIVIDUAL ORGANISMS}

Week 2 (fig 1)

The addition of nucleotides to the formula $(\mathrm{W}+\mathrm{N})$ was associated with: (1) More babies (81\%) were colonised with $E$ coli compared with those fed W $(61 \%)(p=0.04)$ or breast milk $(52 \%)(p=0 \cdot 01)$. (2) Fewer babies $(47 \%)$ were colonised with bifidobacteria compared with breast fed babies $(65 \%)(p=0.012)$. (3) Lower counts of enterococci compared with the W babies $(p=0.01)$ but higher counts than breast fed babies $(p<0.001)$. (4) Lower counts of bifidobacteria than the $W$ babies $(p=0.037)$ and lower than breast fed babies $(p=0.012)$. (5) Higher counts of bacteroides compared with breast fed babies $(p=0.017)$.

Weeks 4 and 7 (table 3)

The only difference between the two formula fed groups of babies was that more babies fed $\mathrm{W}+\mathrm{N}(96 \%)$ were colonised with enterococci at 4 weeks compared with the $W$ group $(77 \%)$ $(p=0.049)$. Other differences were between the breast fed babies and both groups of formula fed babies. More formula fed babies were colonised by enterococci and bacteroides and more breast fed babies were colonised with staphylococci. The bacterial flora of both formula fed groups were similar at week 7 and so the individual results are not shown.

PATTERNS OF DOMINANCE (FIG 2)

At both 2 and 4 weeks of age bifidobacteria were the dominant organisms in the breast fed babies. $E$ coli was the dominant organism at 2 weeks of age in more of the $\mathrm{W}+\mathrm{N}$ babies $(19 \%)$ than the $W$ group $(3 \%)(p=0.043)$. At 4 weeks fewer $\mathrm{W}$ babies (4\%) had bifidobacteria as the dominant organism compared to breast fed babies $(42 \%)(p=0.0074)$. At week 7 there were no differences in the patterns of dominance.

\section{Discussion}

The addition of nucleotides to the whey dominant iron fortified formula did not move the faecal flora closer to that of a breast fed baby. Indeed at 2 weeks the reverse effect was noted with more babies colonised with $E$ coli and a reduction of counts of bifidobacteria.

We have, therefore, not confirmed the results of Gil et al who found that nucleotides enhanced the growth of bifidobacteria in the faecal flora of infants. ${ }^{11} \mathrm{We}$ have considered in some detail why this is so and five possibilities were examined. (1) The microbiological techniques used were different. They were, but the methods were well accepted and each study had its own controls. There seems nothing to suggest the Birmingham techniques were any less sensitive than the Granada ones. (2) The babies were obviously different, but in both centres they were normal healthy newborns, 33 in Granada, 86 in Birmingham. (3) The microbiological environment was obviously different. We know, however, that it was relatively stable in Birmingham because the faecal flora bacterial population examined) analysed statistically by the $\chi^{2}$ test (fig 2 for weeks 2 and 4). 
of the breast fed babies studied at different times over the past eight years has shown little change. ${ }^{12}$ (4) The babies' diets were different. In Granada the babies were fasted for 6-8 hours after birth and received dextrose for 12-24 hours. In Birmingham the test feeds commenced as soon as the baby wished to feed, usually less than 4 hours. The Granada formulas compared with those in Birmingham contained slightly less protein (16 $\mathrm{g}$ compared with $17.5 \mathrm{~g}$ per litre) and more medium chain triglyceride ( $25 \%$ compared with less than $5 \%$ ). The iron and the phosphate content of the Granada formulas were not stated but since they were based on Edamater (a Spanish infant formula) it is likely the values were similar to those in the Birmingham formulas. (5) The amounts of nucleotide added were different.

The nucleotide content of human milk tends to decrease throughout lactation (see table 1). ${ }^{1314}$ The concentrations in colostrum and early milk (48-72 hours) are much higher for cytidine monophosphate, adenosine monophosphate, and uridine monophosphate but decrease rapidly to less than half of that value during the first two weeks of lactation and are subsequently stable.

The concentrations of nucleotides added to the formula in our study were at about the mean level found in the early stages of lactation (48-72 hours). They were therefore, higher than the mean concentrations found in mature breast milk, although within the observed range; they were also much higher than those used by Gil et al. ${ }^{11}$ While it seems unlikely that this higher level of supplementation could account for the fact that we have found a faecal flora even less like that of a breast fed baby in babies fed nucleotide supplemented formula, the possibility cannot be excluded.
Clearly studies from other centres will be necessary to resolve these differences in observation. In the meantime, while there may be arguments for adding nucleotides to an infant formula ${ }^{5-8}$ to mimic the concentrations observed in breast milk, we have found that this addition does not promote a 'breast fed' faecal flora.

This study was partly funded by Wyeth-Ayerst Laboratories, Philadelphia, USA. We are grateful to Mrs C Boyle and Mrs L Borman for the collection of specimens.

1 Balmer SE, Wharton BA. Diet and faecal flora in the newborn: breast milk and an infant formula. Arch Dis newborn: breast milk and

2 Balmer SE, Scott PH, Wharton BA. Diet and faecal flora in the newborn: casein and whey proteins. Arch Dis Child 1989; 64: 1678-84

3 Balmer SE, Scott PH, Wharton BA. Diet and faecal flora in the newborn: lactoferrin. Arch Dis Child 1989; 64: 1685-90.

4 Balmer SE, Wharton BA. Diet and faecal flora in the newborn: iron. Arch Dis Child 1991; 66: 1390-4.

5 Quan R, Barness LA, Uauy R. Do infants need nucleotide supplemented formula for optimum nutrition? 7 Pediatr Gastroenterol Nutr 1990; 11: 429-37.

6 Gil A, Pita ML, Martinez A, Molina JA, Sanchez-Medina F. Effects of dietary nucleotides on the plasma fatty acids in at term neonates. Human Nutrition: Clinical Nutrition at term neonates.

7 Carver JD, Coc WI, Barness LA. Dietary nucleoside effects upon murine natural killer cell activity and macrophage activation. Fournal of Parenteral and Enteral Nutrition 1990; 14: 18-22.

8 Nunez MC, Ayudarte MV, Morales D, Suarez MD, Gil A. Effect of dietary nucleotides on intestinal repair in rats with experimental chronic diarrhea. $\mathcal{F}$ Pediatr Gastroenterol Nutr 1990; 14: 598-604.

9 Gyllenberg H, Carlberg G. The nutritional characteristics of the bifid bacteria (Lactobacillus bifidus) of infants. Acta

10 Tanaka R, Mutai M. Improved medium for selective isolation and enumeration of bifidobacterium. Appl Environ tion and enumeration of

11 Gil A, Corral E, Martinez A, Molina JA. Effects of the addition of nucleotides to an adapted milk formula on the microbial pattern of faeces in at term newborn infants. fournal of Clinical Nutrition and Gastroenterology 1986; 1 : 127-32.

12 Department of Health and Social Security. Composition of mature milk (report 12). London: HMSO, 1977.

13 Janas LM, Picciano MF. The nucleotide profile of human milk. Pediatr Res 1982; 16: 659-62.

14 Gil A, Sanchez-Medina F. Acid soluble nucleotides of human milk at different stages of lactation. $\mathcal{F}$ Dairy Res 1982; 49: 301-7. 